\title{
Investigation of Nanosized Crystalline Form to Improve the Oral Bioavailability of Poorly Water Soluble Cilostazol
}

\author{
Xiaoqing Miao ${ }^{1}$; Changshan Sun ${ }^{1}$; Tongying Jiang ${ }^{1}$; Li Zheng ${ }^{1}$; Tianyi Wang ${ }^{1}$; Siling Wang ${ }^{1}$ \\ ${ }^{1}$ Department of Pharmaceutics, Shenyang Pharmaceutical University, Shenyang, PR China \\ Received, January 16, 2011; Revised, April 3, 2011; Accepted, May 18, 2011; Published, May 19, 2011
}

\begin{abstract}
Purpose: The aim of this study was to develop cilostazol (CLT) nanocrystals intended to improve its dissolution rate and enhance its bioavailability. Methods: In this study, CLT nanosuspension was prepared by the anti-solvent and high-pressure homogenization method. The effects of the production parameters, such as the stabilizer concentration, pressure and number of cycles, were investigated. Then the CLT nanosuspensions were sprayed to dry powders. Characterization of the product was performed by scanning electron microscopy (SEM), Nitrogen adsorption, differential scanning calorimetry (DSC), X-ray powder diffraction analysis (XRPD), X-ray Photoelectron Spectroscopy (XPS), particle size analysis and dissolution testing. Additionally, the comparison studies of oral relative bioavailability in beagle dogs of two type tables were performed. Results: The images of SEM showed a spherical smooth CLT powder, and Nitrogen adsorption test revealed spray dried powder were porous with high BET surface area compared with that of raw CLT. DSC and XRPD results demonstrated that the combination of preferred polymorph B and C of CLT were prepared successfully, the saturation solubility of the nanosized crystalline powder is about 5 fold greater than that of raw CLT, and the dissolution rate was enhanced 4 fold than that of raw CLT. The Cmax and $\mathrm{AUC}_{0-48 \mathrm{~h}}$ of CLT nanosized crystalline tablets were 2.1 fold and 1.9 fold, and 3.0 fold and 2.3 fold compared with those of the nanosized tablets and commercial tablets, respectively. Conclusion: The anti-solvent-high-pressure homogenization technique was employed successfully to produce cilostazol nanosuspensions. The bioavailability of CLT tablets prepared using spray dried nanosized crystalline powder after oral administration to dogs was markedly increased compared with that produced by nanosized tablets and commercial tablets, because of its greater dissolution rate owing to its transition of the crystalline state to form $\mathrm{C}$ and form $\mathrm{B}$, reduced particle size and porous structure with increased surface area.
\end{abstract}

This article is open to POST-PUBLICATION REVIEW. Registered readers (see "For Readers") may comment by clicking on ABSTRACT on the issue's contents page.

\section{INTRODUCTION}

A surprisingly large proportion of solid active pharmaceutical ingredients (API) have poor aqueous solubility and dissolution rate, and therefore poor bioavailability. Hence, improving the saturation solubility and dissolution rate of poorly water soluble drugs is very important and significantly challenging.

In recent years, nanoparticle engineering has been seen as a promising approach for the enhancement of drug solubility (1-2). The dissolution rate of a solid drug can be expressed by the Noyes-Whitney equation (3-4), and it is also well known that the dissolution rate can be proportionally increased by increasing the surface area as a consequence of comminution. Unlike micronization, nanonization often increases the solubility as well as the dissolution rate (5). There are two general techniques for the production of drug nanocrystals, 'bottom-up' and 'top-down' processes (6). The top-down technologies involve the breaking down of large particles to form nanocrystals, which include high-pressure homogenization (HPH) (7-9) and media milling methods (10). The bottom-up approach can build up crystals by precipitation of dissolved molecules (11).

Nowadays, nanosize particles of some poorly water soluble drugs have been produced by a top-down or bottom-up approach alone, however,

Corresponding Author: Siling Wang, Department of Pharmaceutical University, No.103, Wenhua Road, Shenyang 110016, PRChina; Email: silingwang@syphu.edu.cn 
researchers have rarely obtained nanocrystals by a combination of the bottom-up and top-down approaches. As we known, there is no study regarding the CLT nanocrystals prepared by anti-solvent precipitation under sonication has been yet published. In this study, we employed the combination of the above two techniques, the anti-solvent and high-pressure homogenization method, to obtain small and uniform nanocrystals.

Cilostazol, 6-[4-(1-cyclohexyl-1H-tetrazol-5-yl) butoxy]-3, 4-dihydro-2(1H)-quinolinone, (the chemical structure is shown in Figure 1) and several of its metabolites, are inhibitors of phosphodiesterase III, it also suppresses platelet aggregation and is a direct arterial vasodilator (12-14). According to the Biopharmaceutics Classification System (BCS), CLT is categorized as a Class II agent (poorly water soluble and highly permeable) (15). Cilostazol is a neutral molecule having an aqueous solubility of $3 \mu \mathrm{g} / \mathrm{mL}$ deterimined in water at $25^{\circ} \mathrm{C}$ with the molecular weight and melting point of cilostazol are 369.47 and $159.4-160.3^{\circ} \mathrm{C}$, respectively (16), and relatively high apparent permeability coefficient in Caco-2 cell monolayers $\left(2 \times 10^{-6} \mathrm{~cm} / \mathrm{s}\right)$ (17). The study by Bramer and Forbes (18) suggests that the incomplete absorption of CLT from the tablet form in humans is likely due to its poor dissolution. The investigation of Jun-ichi Jinno et al (19) showed that reducing the particle size by media milling method can improve the dissolution and oral absorption of CLT, and they established a good in vitro-in vivo correlation (20). However, from the above investigation, conventional techniques like the use of inclusion complexes (21), and micronization using a supercritical anti-solvent (SAS) (22-23) did not change the crystalline form and, did not improve the bioavailability further more. Stowell et al. (24) reported that CLT has three different polymorphic forms, $\mathrm{A}, \mathrm{B}$ and $\mathrm{C}$.
Form $\mathrm{B}$ and $\mathrm{C}$ possess distinct advantages over the form A of CLT. To our knowledge no study regarding the CLT nanocrystals existing by preferred crystalline form nanocrystals has been yet published.

In present study, the anti-solvent-high-pressure homogenization technique was employed successfully to prepare small and uniform cilostazol nanocrystals with a reduced particle size. At the same time, by controlling the parameters, the transition of the crystalline state to form $\mathrm{C}$ and form $\mathrm{B}$ occurred. The potential for the bioavailability enhancement of CLT nanocrystals was further investigated by spray drying and then formulation into immediate release tablets. Bioavailability study in beagle dogs of three types of tablets (nanosized crystalline tablets, nanosized tablets and commercial tablets) were evaluated. The bioavailability of nanosized crystalline tablets after oral administration to dogs was markedly increased compared with that produced by nanosized tablets and commercial tablets.

\section{MATERIALS AND METHODS}

\section{MATERIALS}

CLT (Yiwu Gaodeng Jixie Chemical Engineering Co., Ltd), and the purity of the drug is $99.8 \%$ measured by HPLC; Hydroxypropyl methylcellulose (HPMC E5) was a gift from Dow Chemical Company (America); commercial tablets (Pletaal ${ }^{\circledR} \quad 50-\mathrm{mg}$ tablets, prepared with hammer-milled cilostazol) were purchased from Zhejiang Otsuka Pharmaceutical Co., Ltd. (Zhejiang, China); All the materials and powders were stored at a vacuum dryer at room temperature; All other chemicals were of analytical grade used as received. Water was purified by reverse osmosis.

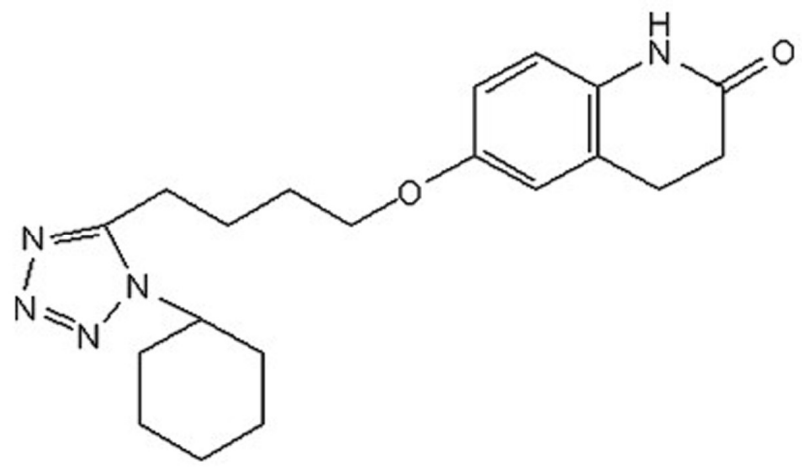

Figure 1. Chemical structure of Cilostazol 


\section{METHODS}

Preparation of cilostazol nanosuspensions by anti-solvent-high-pressure homogenization method

The preparation procedure is as follows, briefly, 1.2 $\mathrm{g}$ raw CLT was dissolved in $10 \mathrm{~mL}$ $\mathrm{N}$-methyl-2-pyrrolidone (NMP), which was used as solvent; $0.4 \mathrm{~g} \mathrm{HPMC(E5)} \mathrm{was} \mathrm{dissolved} \mathrm{in} 200 \mathrm{~mL}$ deionized water which was used as anti-solvent. The ratio of solvent to anti-solvent was 1:20. The drug solution was injected rapidly into the anti-solvent and then sonicate by a probe sonicator (JY92-II, Scientz, Ningbo, China) for intermittent sonication (ultrasonic for 3 seconds, interval 2 seconds, 30times). The suspensions were kept under vacuum at room temperature for $1 \mathrm{~h}$ to remove the NMP. Subsequently, the obtained pre-suspension was homogenized using an ATS AH110D homogenizer (ATS Engineer Inc. China). The homogenization process consists of ten cycles at 200 bar and another 15 cycles at 600 bar for pre-milling, followed by 20 cycles at 1000 bar to obtain the CLT nanosuspensions. The temperature of the suspension was maintained at $-10^{\circ} \mathrm{C}$ during the process by employing a circulating ethanol bath (DL-1005, Ningbo Scientz Biotechnology Co., Ltd, China).

\section{Spray drying of nanosuspensions}

Prior to spray drying, $0.4 \mathrm{~g}$ mannitol was added to $200 \mathrm{~mL}$ nanosunpensions as protecting agent. A EYELA SD-1000 Spray Dryer (Tokyo Rikakikal. Co., Ltd., Japan), with inlet temperatures of 70, 90, $100,110,130$ and $140^{\circ} \mathrm{C}$ and outlet temperatures $50-80^{\circ} \mathrm{C}$ operated at a solution pumping rate of 2.0 $\mathrm{mL} / \mathrm{min}$, with an atomizing air flow rate of 0.6 $\mathrm{m}^{3} / \mathrm{min}$, was used to prepare the stabilized CLT nanocrystals. The dry powder with nanosized CLT exhibited good uniformity and the yield of dry powder was approximately $70 \%$.

\section{Nanocrystals characterization \\ Particle-size analysis}

Particle size analysis of the nanosuspensions was measured by laser diffraction (LD) using a Coulter LS 230 instrument from Beckmann-Coulter Electronics (Krefeld, Germany). Laser diffraction yields volume-weighted particle size distribution over the size range 0.040 to $2000 \mu \mathrm{m}$ particle-size distribution. The suspensions were analyzed without dilution and the dispersing liquid used for the laser diffraction measurements is distilled water.
Scanning electron microscopy (SEM)

The morphology of the pure materials, coarse suspensions, nanosuspensions, and spray dried powder was characterized using a SEM instrument (JSM-6301F, JEOL, Japan) operated at an excitation voltage of $20 \mathrm{kV}$. The samples were fixed on a brass stub using carbon doublesided tape and deposited following the evaporation of solvent and gold-plated prior to recording images. After degree of vacuum reach 0.2-0.02 Torr, the gold plating performed for 100-120 second to form 10-20 nm thickness of golden layer.

\section{Nitrogen adsorption}

Nitrogen adsorption isotherms were obtained using a SA3100 surface area analyzer (Beckman coulter, USA). Raw CLT and spray dried powder were degassed at $100{ }^{\circ} \mathrm{C}$ for $3 \mathrm{~h}$. The pore size distributions and pore volumes were determined according to the Brunauer-Emmett-Teller (BET) and Barrett-Joyner-Halenda $(\mathrm{BJH})$ procedures.

\section{Differential scanning calorimetry (DSC)}

DSC analysis were performed using a TA-60WS Thermal Analyzer (Shimadzu, Japan) and a low temperature DSC (Mettler-Toledo, Switzerland), respectively. The samples approximately 2-3 mg based on the AP content of the formulation were weighed into hermetically sealed aluminum pans and heating curves were recorded from 30 to $200^{\circ} \mathrm{C}$ at $10^{\circ} \mathrm{C} / \mathrm{min}$ and with a nitrogen purge of 40 $\mathrm{mL} / \mathrm{min}$, and samples were accurately weighed to be $1.50 \mathrm{mg}$ and encapsulated in pierced aluminum pans. The measurements were performed from 0 to $200{ }^{\circ} \mathrm{C}$ using a heating rate of $10{ }^{\circ} \mathrm{C} / \mathrm{min}$ under a $\mathrm{N}_{2}$ gas purge of $30 \mathrm{~mL} / \mathrm{min}$, respectively.

\section{X-ray powder diffraction analysis (XRPD)}

XRD patterns of the samples were recorded using an X-ray diffractometer (Rigaku Geigerflex XRD, Co., Japan) with a $\mathrm{Cu}-\mathrm{Ka}(\lambda=1.54 \AA)$ target. The $\mathrm{X}$-rays were carried out at $30 \mathrm{kV}$ and $30 \mathrm{~mA}$ Philips. Data were obtained from $5^{\circ}$ to $40^{\circ}$ (diffraction angle) with a scanning rate of $4 \%$ min radiation and a step size of $0.02^{\circ}$.

\section{Analysis of surface composition}

X-ray Photoelectron Spectroscopy (XPS) is also known as Electron Spectroscopy for Chemical Analysis (ESCA). XPS was used to investigate the elemental composition of the powder surfaces with an analysis depth of less than $100 \AA$. The XPS measurements were performed with an AXIS HS 
photoelectron spectrometer (ESCALAB250, Thermo VG., USA). The instrument uses a monochromatic Al-Ka X-ray source of $150 \mathrm{~W}$ with operating voltage of $15 \mathrm{kV}$. Binding energy range was from 0 to $1300 \mathrm{eV}$ and the average peak binding energy of $\mathrm{C} 1 \mathrm{~s}, \mathrm{~N} 1 \mathrm{~s}$ and $\mathrm{O} 1 \mathrm{~s}$ were 285 , 399.81 and $532.19 \mathrm{eV}$, respectively. All spectra were baseline subtracted and fitted using Gaussian function.

\section{Preparation of tablet formulation}

Nanosized tablets (prepared by nanosized spray dried powder) and nanosized crystalline tablets (prepared by nano-size crystalline spray dried powder) were preapred. Due to the good compressibility of spray dried powder (during tablet preparation process, spray dried powder was easy to compressed to a tablet directly), lactose (sephrolac 100, a kind of spray dried lactose) was used as filler. $15 \%$ of Croscarmellose sodium (SD-711) was selected to be disintegrating agent because of good disintegrating ability and compressibility. The CLT spray dried powder and lactose in the ratio $4: 1$ were carefully mixed using a pestle and mortar, then the compositions were pass to a 100 mesh sieve. $1 \%$ of magnesium stearate was added to all compositions before compression. CLT spray dried powder was compressed into $120 \mathrm{mg}$ tablets (the same weight as commercial tablets) with lactose and croscarmellose sodium using a universal tester (AutographAG-I 50KN, Shimadzu, Kyoto, Japan) equipped with a $7.0 \mathrm{~mm}$ i.d. at 5-6 $\mathrm{KN}(25)$.

\section{Solubility measurement}

To evaluate the impacts of the reduction of particle size and preferred crystalline form nanocrystals effect on equilibrium solubility, equilibrium solubility values of CLT at $37^{\circ} \mathrm{C}$ were determined in water to evaluate the solubility of different particle sizes (spray dried 1232, 667, $326 \mathrm{~nm}$ powders) and different inlet temperatures (different crystalline form nanocrystals can be prepared) of spray dried powders (the inlet temperatures are 70 , $90,100,110,130$ and $140^{\circ} \mathrm{C}$ respectively).

An excess amount of spray dried powder of different particle sizes and different inlet temperatures were added to a series of conical flasks. Then, the flasks were shaken continuously in a water bath maintained at $37{ }^{\circ} \mathrm{C}$ for $24 \mathrm{~h}$. The equilibrated samples were immediately passed through a $0.2 \mu \mathrm{m}$ membrane filter, and a $10 \mu \mathrm{L}$ volume of each sample was analyzed by reversed phase HPLC. The solubility of the samples were analyzed by a Hitachi ${ }^{\mathrm{TM}}$ HPLC system consisting of a L7000 pump and a L7420 UV-VIS tunable absorbance detector (Japan), with the detection wave-length of $257 \mathrm{~nm}$. A kormasil C18 column (4.6 mm $\times 200 \mathrm{~mm} \mathrm{5um,} \mathrm{Sweden)} \mathrm{was} \mathrm{used} \mathrm{as} \mathrm{the}$ analytical column and the mobile phase consisted of a 50:50 (v/v) mixture of acetonitrile and water delivered at $1.0 \mathrm{~mL} / \mathrm{min}$. The measurements were repeated three times.

\section{Cilostazol dissolution studies}

Dissolution studies were evaluated by the cumulative dissolution percentage of drug released. Dissolution study was carried out by the paddle method of Chinese Pharmacopoeia 2002 (RC-8D, Tianjin Guoming Medical Equipment Co., Ltd, China). The dissolution medium used was $500 \mathrm{~mL}$ of $0.3 \%$ SDS solution, which was incubated in a water bath at $37{ }^{\circ} \mathrm{C}$. The rotation speed of the paddle was $75 \mathrm{rpm}$ and samples were taken at following times $(5,10,15,20,30,4560,85,120$ min). Dissolved CLT was quantified with a UV spectrophotometer at a wavelength of $257 \mathrm{~nm}$ (the max peak).

\section{Bioavailability studies in beagle dogs Animals and dosing procedure}

Male and female pure-bred beagle dogs (body weight 10-15 $\mathrm{kg}$ ) were supplied by the Experimental Animal Center of Shenyang Pharmaceutical University (Shenyang, China). The animal experiment was evaluated and approved by the Animal Ethics Committee, Shenyang Pharmaceutical University. Cilostazol was orally administered to six beagle dogs (body weight 10-15 $\mathrm{kg})$ as the there types of tablets $(\mathrm{n}=6)$, the commercial tablets, and the nanosized tablets and nanosized crystalline tablets at a dose of $100 \mathrm{mg} /$ body (two tablets) in a crossover design and the washout period of between doses is 1 week. The dogs were fasted for $10 \mathrm{~h}$ before dosing and allowed free access to water throughout the experiment. Blood samples $(5 \mathrm{~mL})$ were collected from a forearm vein at 0 (pre-dose), $0.5,1,2,3,4,6,812$, $16,24,36$ and $48 \mathrm{~h}$ following oral dosing. Serum samples were obtained by centrifugation at 3000 $\mathrm{r} / \mathrm{m}$ for $10 \mathrm{~min}$ and then stored at $-20{ }^{\circ} \mathrm{C}$ for analyzing by HPLC.

\section{Data analysis of CLT in plasma}

CLT was determined by HPLC (Hitachi L7000 pump equipped with L-7420UV-VIS detector, 
Japan) method. A kormasil C18 column (4.6 $\mathrm{mm} \times 200 \mathrm{~mm} 5 \mathrm{um}$, Sweden) was used as the analytical column and the mobile phase consisted of a 45:55 (v/v) mixture of acetonitrile and water delivered at $1.0 \mathrm{~mL} / \mathrm{min}$. UV-detection was performed at $257 \mathrm{~nm}$. Diazepam was employed as the internal standard. Frozen plasma samples were thawed to reach room temperature. Plasma $(500 \mu \mathrm{L})$ was placed into a test tube, $10 \mu \mathrm{L}$ internal standard solution $(15 \mu \mathrm{g} / \mathrm{mL}), 1 \mathrm{~mL} \mathrm{NaOH}(0.5 \mathrm{~mol} / \mathrm{L})$ and 3 $\mathrm{mL}$ diethyl ether were added subsequently. The tubes were mixed by vortexing (XW-80A, Shanghai, China) for $3 \mathrm{~min}$, centrifuged at $3500 \mathrm{r} / \mathrm{m}$ for $10 \mathrm{~min}$. The organic layer was transferred to a clean test tube and evaporated by centrifugal at $50^{\circ} \mathrm{C}$ (Labconco Centrivap, USA). The residues were reconstituted in $100 \mu \mathrm{L}$ of mobile phase, mixed well and $20 \mu \mathrm{L}$ of the final clear solution was injected into the HPLC system.

Calibration curves were drawed by plotting the measured peak area ratios of CLT to Diazepam concentrations of standard samples. The recovery of CLT in plasma was calculated from recovery $=$ CLT peak area in plasma sample /CLT peak area in methanol sample. The percent recovery of CLT from plasma in the low $(\mathrm{C}=100 \mathrm{ng} / \mathrm{mL})$, medium $(\mathrm{C}=800 \mathrm{ng} / \mathrm{mL})$ and high concentration $(\mathrm{C}=1600$ $\mathrm{ng} / \mathrm{mL}$ ) were determined to be $101.7 \pm 8.06 \%$, $103.6 \pm 10.7 \%$, and $99.8 \pm 10.2 \%$. The analytical precision of cilostazol in plasma for Intra-day and Inter-day are shown in Table 1. Standard pharmacokinetic $(\mathrm{PK})$ parameters $( \pm$ S.D.) of CLT were derived from plasma concentration-time curves using DAS 2.1 software. The various PK parameters that were analyzed included maximum peak concentration of the drug in plasma (Cmax), the time to reach maximum concentration (Tmax), and the area under the curve (AUC 0-48h). The assay validation data are presented in Table 5 .

\section{RESULTS}

\section{Preparation of cilostazol nanosuspensions}

In our work, CLT nanocrystals were successfully prepared by the combination of anti-solvent precipitation and HPH. During preparation, we studied the effects of the concentration of stabilizer, the homogenization pressure and the number of cycles on the particle size of the nanosuspensions.

The effect of the stabilizer concentrations on the particle size varied from $0.1,0.2,0.3$ to $0.4(\%, \mathrm{w} / \mathrm{v})$ was investigated. Figure 2 shows that when the HPMC concentration was $0.1 \%$, the mean particle size was about $1.7 \mu \mathrm{m}$. However, when the concentration was over $0.2 \%$, the particle size was not markedly reduced, which indicated that the drug particle surface was already absorbed sufficiently stabilizer molecules.

Figure 3 shows that when the homogenization pressure was varied from 800 to 1000 bar, the particle size of the final nanosuspensions did not show markedly reduced at a higher homogenization, but it was greater at 600 bar. With the number of homogenization cycles increased, the particle size firstly decreased and then increased slightly. As it can be seen, the smallest particle size was obtained after 20 homogenization cycles. The particle size of the final nanosuspensions was mainly affected by the homogenization pressure and number of cycles. The role of the length of ultra-sonication was relatively unimportant.

Therefore, the optimal formulation is as follows: the concentration of stabilizer solution, homogenization pressure and number of cycles are selected as $0.2 \%, 1000$ bar and 20 , respectively.

Table 1. Relative recovery and analytical precision of cilostazol in plasma by HPLC ( $\mathrm{n}=15$; five sets for 3 days)

\begin{tabular}{|c|c|c|c|c|c|c|c|}
\hline \multirow[b]{2}{*}{$\begin{array}{c}\mathrm{C}_{\text {added }} \\
(\mathrm{ng} / \mathrm{mL})\end{array}$} & \multirow[b]{2}{*}{$\begin{array}{c}\mathrm{C}_{\text {detected }}(\mathrm{ng} / \mathrm{mL}) \\
\text { Mean } \pm \mathrm{SD}\end{array}$} & \multirow[b]{2}{*}{$\begin{array}{c}\text { Recovery } \\
(\%)\end{array}$} & \multirow[b]{2}{*}{$\begin{array}{l}\text { RSD } \\
(\%)\end{array}$} & \multicolumn{2}{|c|}{ Intra-day $(\mathrm{n}=5)$} & \multicolumn{2}{|c|}{ Inter-day $(\mathrm{n}=15)$} \\
\hline & & & & Mean (\%) & $\begin{array}{l}\text { RSD } \\
(\%)\end{array}$ & $\begin{array}{c}\text { Mean } \\
(\%)\end{array}$ & $\operatorname{RSD}(\%)$ \\
\hline 100 & $101.71 \pm 8.22$ & 101.7 & 8.06 & 101.72 & 8.06 & 102.14 & 8.49 \\
\hline 800 & $828.83 \pm 90.45$ & 103.6 & 10.7 & 806.42 & 3.03 & 838.83 & 10.7 \\
\hline 1600 & $1598.21 \pm 178.26$ & 99.8 & 10.2 & 1702.33 & 3.19 & 1852.64 & 5.45 \\
\hline
\end{tabular}




\section{Nanocrystals characterization SEM analysis}

The morphology of the raw CLT and precipitated drug particles is shown in Figure 4. It can be seen that the raw drug particles are white crystalline powder made up of needlelike shaped particles with a broad particle size distribution from 1 to $200 \mu \mathrm{m}$ exhibiting a broad particle size distribution (Figure 4A). The drug particles precipitated with HPMC as a stabilizer had a cuboidal shape with a length of $\sim 3000 \mathrm{~nm}$, a width of $\sim 500 \mathrm{~nm}$ (Figure 4B). However, after HPH, the large particles disappeared and the drug particles became small and uniform (Figure 4C). Figure 4D shows a spherical smooth CLT powder with many pores obtained by spray drying, so, when the powder was dispersed in the media, the water penetrates into the powder quickly via the pores. It was clearly seen that stabilizers were adsorbed onto the drug particle surface inhibiting particle growth.

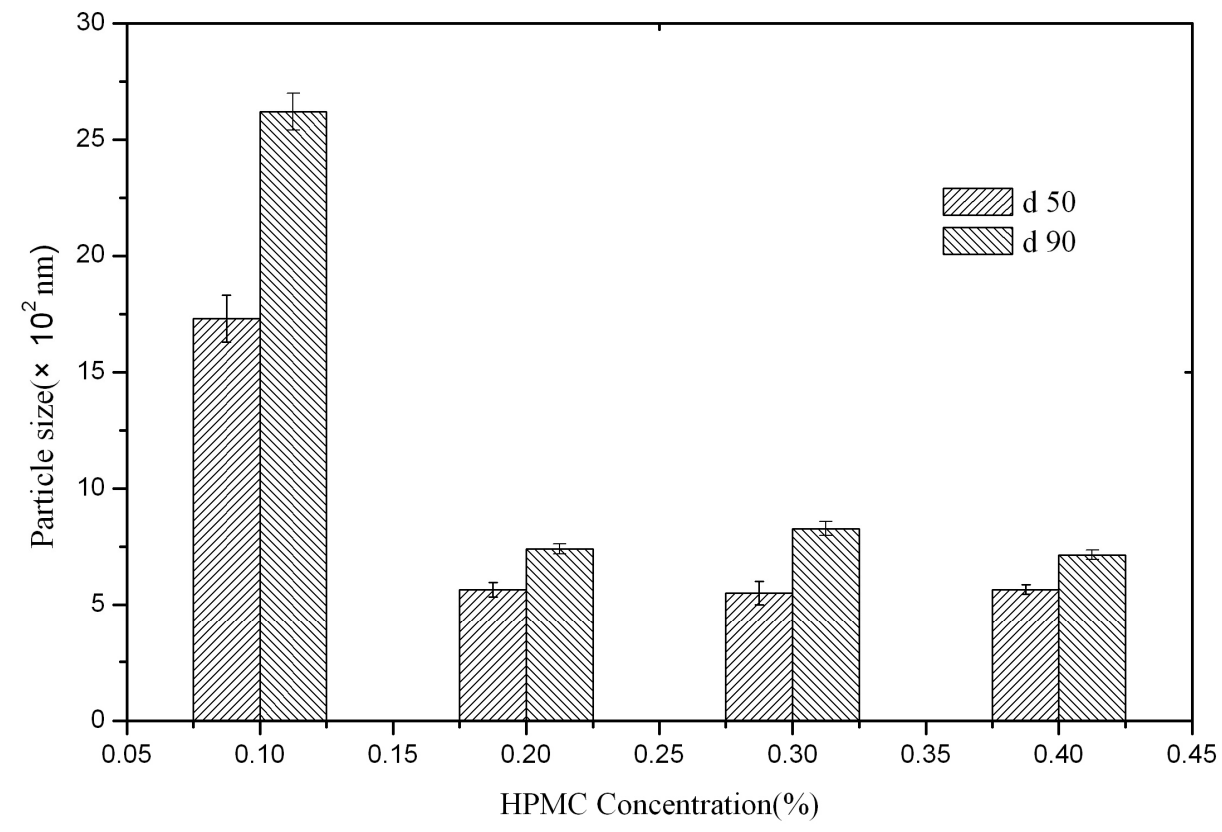

Figure 2. Influence of the concentration of stabilizer solution (the concentration are $0.1 \%, 0.2 \%, 0.3 \%$ and $0.4 \%$, $\mathrm{w} / \mathrm{v})$ ) on the particle size reduction of cilostazol nanosuspensions $(\mathrm{n}=3)$.

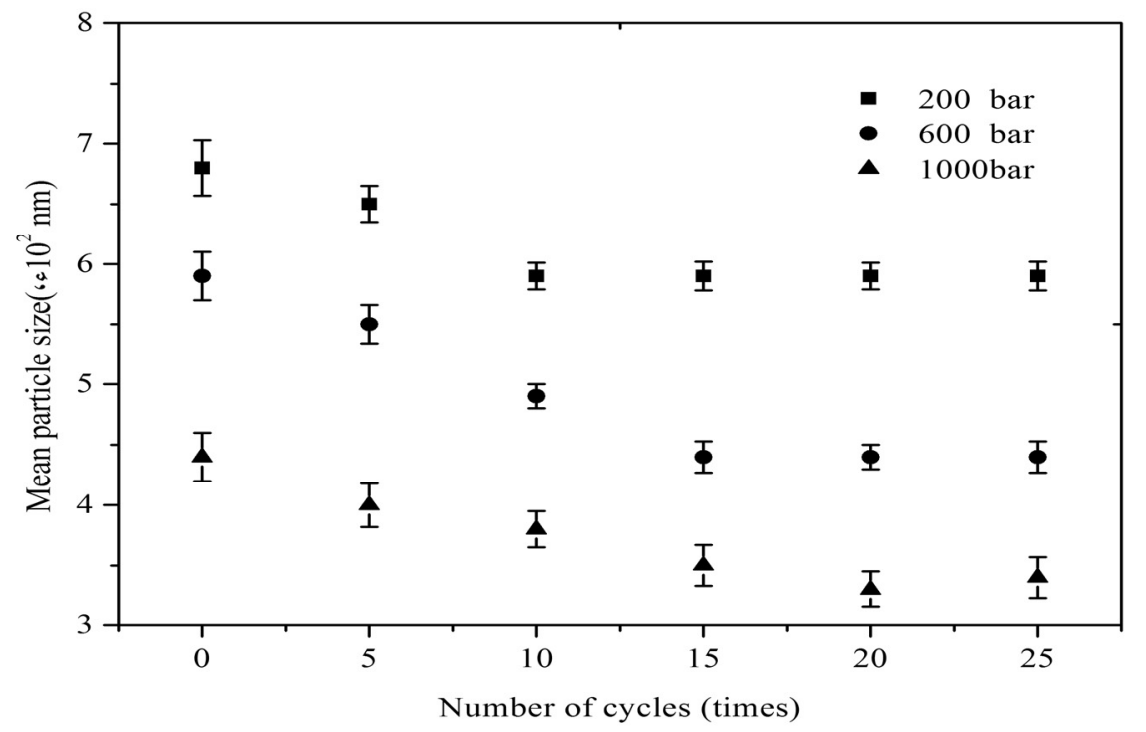

Figure 3. Influence of homogenization pressure and homogenization cycles (n=3) (1) 200bar, (2) 600bar and (3) $1000 \mathrm{bar}$ on the particle size reduction of cilostazol nanosuspensions. 

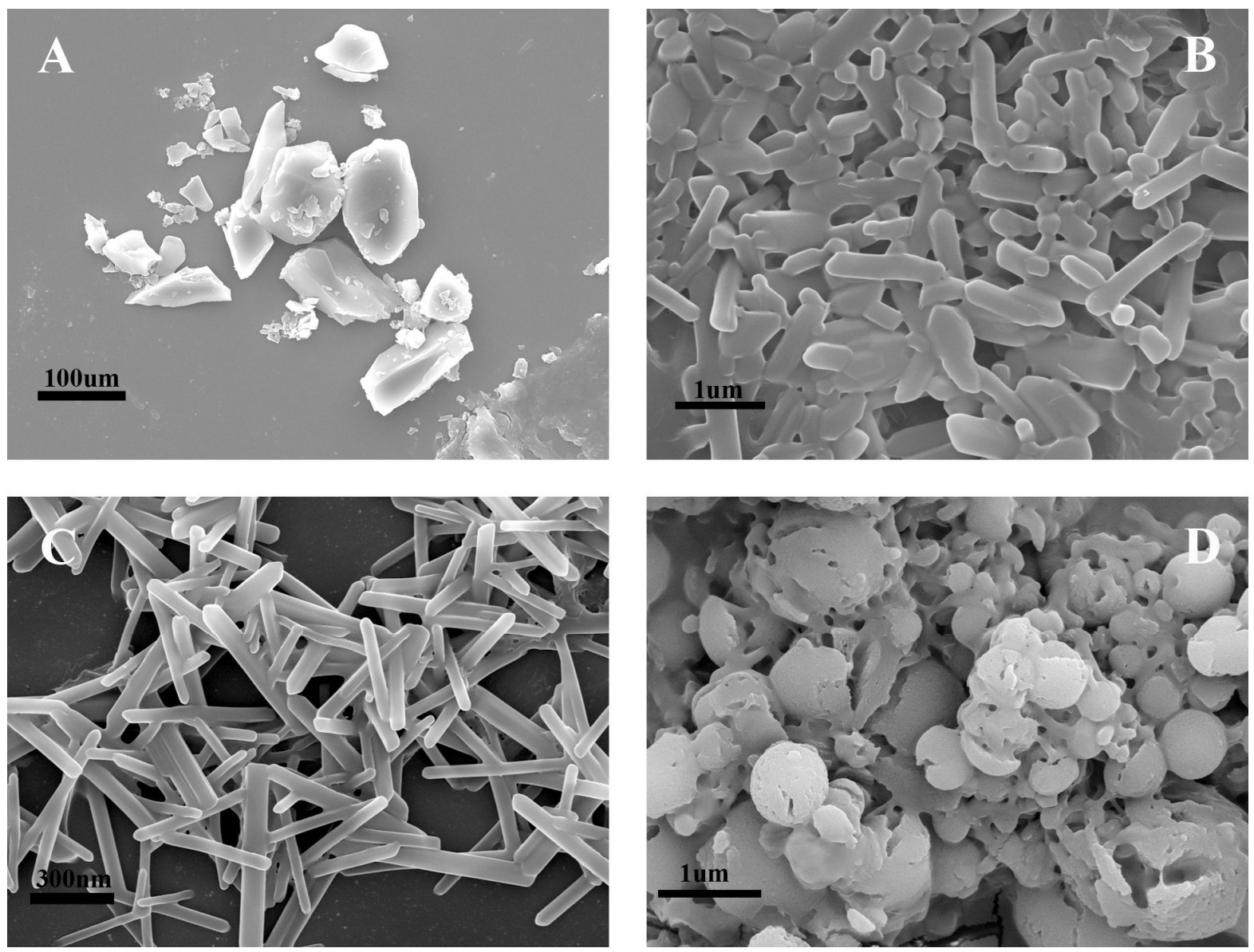

Figure 4. SEM images of (A) raw CLT, (B) drug nanocrystals achieved by anti-solvent method, (C) drug nanocrystals achieved by HPH and (D) spray dried powder.

\section{Nitrogen adsorption}

The morphological characterization of raw CLT and the spray dried powder is shown in Figure 4. Raw CLT, as shown in Figure 5(2), were irregular with low BET surface area $\left(1.7 \mathrm{~m}^{2} \mathrm{~g}^{-1}\right)$. In comparison, the CLT spray dried powder, as shown in Figure $5(1)$, were porous sphere with high BET surface area $\left(10.2 \mathrm{~m}^{2} \mathrm{~g}^{-1}\right)$. Meantime, the mean pore diameter of raw CLT and spray dried powder are $42 \mathrm{~nm}$ and $5 \mathrm{~nm}$ respectively. The existing of pore in spray dried powder shows a great advantage on dissolution behaviour. Hai-Xia Zhang et al. (26)'s investigation shows that, the increased dissolution rate of ultrafine $\mathrm{AC}$ (Amorphous atorvastatin calcium) could be attributed to the great reduction of particle size, the corresponding increased specific surface area (from $4.8 \mathrm{~m}^{2} / \mathrm{g}$ of raw AC to $9.5 \mathrm{~m}^{2} / \mathrm{g}$ of ultrafine $\mathrm{AC}$ ) and the amorphous nature of the product.

\section{DSC}

As the investigation of Stowell et al.(24), characterization of form $\mathrm{A}$, form $\mathrm{B}$, and form $\mathrm{C}$ of cilostazol was further completed using DSC thermograms and XRPD. The DSC thermogram for form $\mathrm{A}$, form $\mathrm{B}$ and form $\mathrm{C}$ give the endothermic peak at about $162{ }^{\circ} \mathrm{C}, 140^{\circ} \mathrm{C}$ and $150^{\circ} \mathrm{C}$, respectively.

The coarse drug powders (Figure 6(1)) exhibited a sharp melting, with an onset temperature of $160.67^{\circ} \mathrm{C}$ and a peak of $163.49^{\circ} \mathrm{C}$. In the spray dried powder (Figure 6(5)), the endothermic peaks of CLT drifted $12.5^{\circ} \mathrm{C}$ and $23.2^{\circ} \mathrm{C}$ to the left, which corresponded to its melting point due to the transition of the crystalline state from form A to form $\mathrm{C}$ and form $\mathrm{B}$, which indicated that stabilizers changed the physical state of CLT in the physical mixture. Figure 7 shows the DSC curves of different inlet temperatures during the spray drying process. During spray drying process, when the inlet temperature is $70^{\circ} \mathrm{C}$, the crystalline form of 
raw CLT is not changed, and the content of polymorph $\mathrm{A}$ is $100 \%$. However, when the inlet temperature is $90,100,110,130$ and $140{ }^{\circ} \mathrm{C}$ during spray drying process, the content of polymorph $\mathrm{A}$ changed a lot. From Figure 7, we can see that when the inlet temperature is $130^{\circ} \mathrm{C}$, the crystalline state is a mixture of form $\mathrm{C}$ and a small amount of form $\mathrm{B}$ without any form A. It indicated preferred polymorph $\mathrm{B}$ and $\mathrm{C}$ of CLT was prepared successfully.

Structural analysis of cilostazol in
nanosuspensions (XRPD) The XRD peaks demonstrated that the significant peaks of form A (greater than $8 \%$ ) are typically located at two-theta angles of about 9.4, 10.3, $12.9,15.3,15.8,18.8,19.4,20.4,20.8,22.0,23.5$ and $31.7^{\circ}$. For form $\mathrm{B}$, the significant XRD peaks are at two-theta angles of about 10.7, 14.2, 14.7, 15.8, 16.6, 17.9, 18.8, 20.4, 21.6, 22.4, 22.8, 23.5, $24.8,25.9,26.8,29.7,30.2$, and $30.7^{\circ}$. For form C, the significant XRD peaks are at two- theta angles of about 8.6, 9.7, 10.1, 13.1, 16.7, 17.3, 19.4, 20.2, 23.7 and $25.7^{\circ}$. To confirm the physical state of spray dried powder, X-ray diffraction was further performed. Figure 8 shows the $\mathrm{X}$-ray diffraction patterns of the raw CLT, mannitol, HPMC, blank excipients, the mixture of CLT (form A) and excipients, and spray dried CLT powder. The diffraction pattern of raw CLT showed characteristic high-intensity diffraction peaks at 9.4, $10.3,12.9,15.3,15.8,18.8,19.4,20.4,20.8,22.0$, 23.5 , and $31.7^{\circ}$ of $2 \theta$ that matched those known for CLT form A (27).

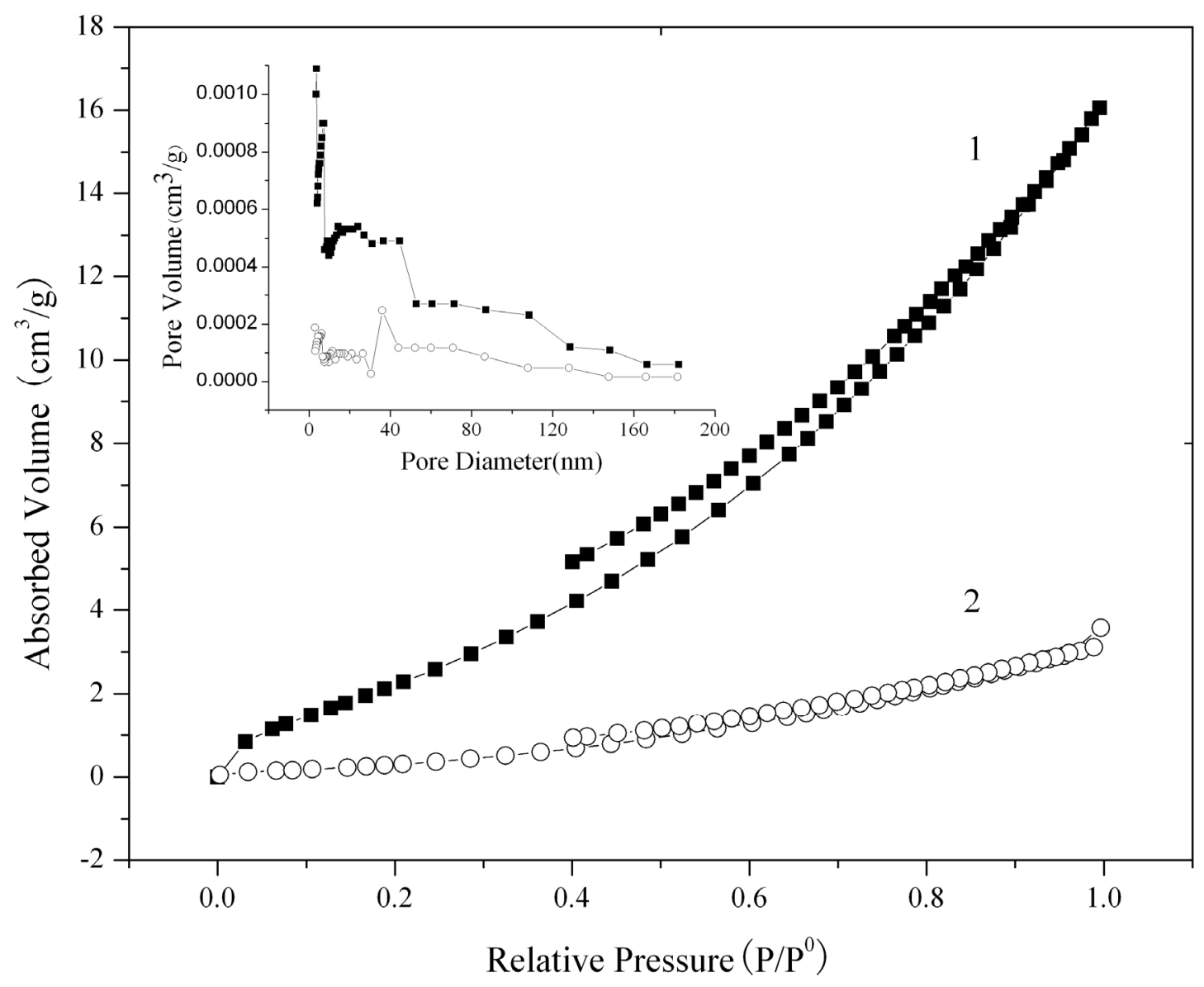

Figure 5. Nitrogen adsorption/desorption isotherms of Raw CLT (1), and Spray dried powder (2). 


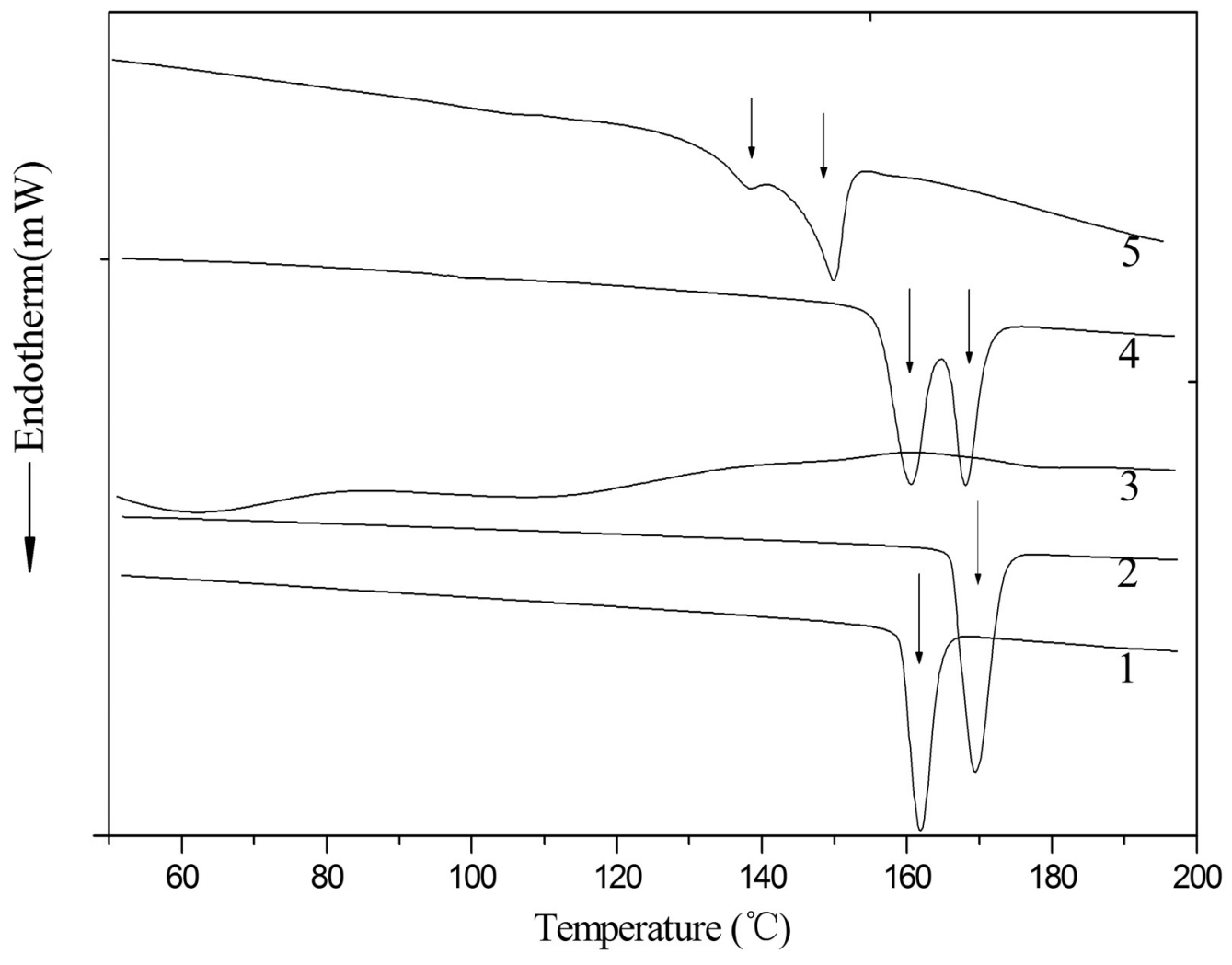

Figure 6. Differential scanning calorimetry curves of raw CLT (1), mannitol (2), HPMC (3), mixture of CLT and blank excipients (4) and spray dried powder (5).

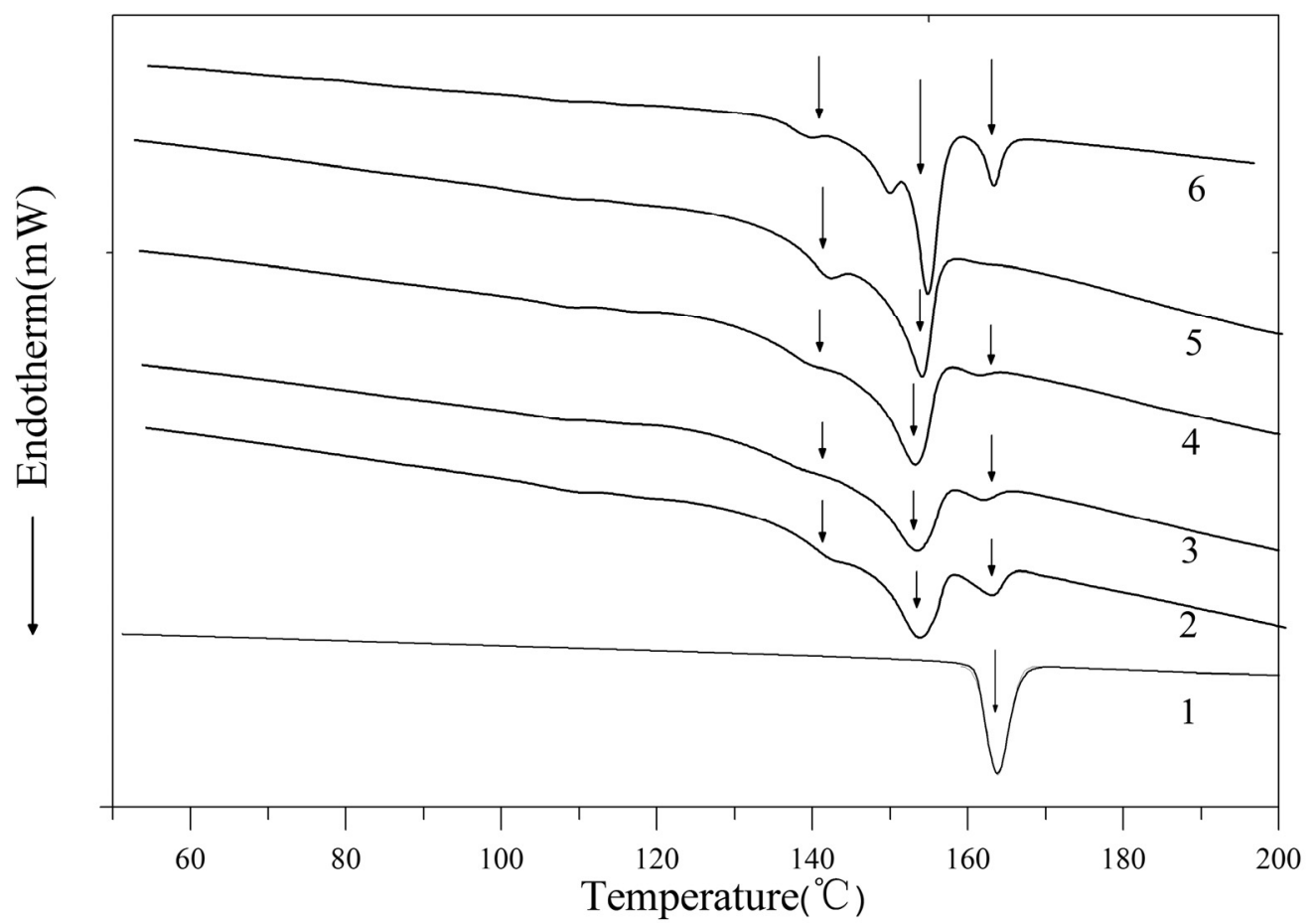

Figure 7. Differential scanning calorimetry curves of different inlet temperatures ((1) $70^{\circ} \mathrm{C}$, (2) $90^{\circ} \mathrm{C}$, (3) $100^{\circ} \mathrm{C}$, (4) $110^{\circ} \mathrm{C}$, (5) $130^{\circ} \mathrm{C}$ and (6) $140^{\circ} \mathrm{C}$ ) during spray drying process. 
The characteristic diffraction peaks at two-theta angles of about 8.6, 9.7, 10.1, 13.1, 16.7, 17.3, 19.4, $20.2,23.7$ and $25.7^{\circ}$ were observed at a different $2 \theta$ position, indicating that the crystalline structure of the drug had changed to form $\mathrm{C}$ and a small amount of form B after the spray drying process. As shown in Figure 8(6), the characteristic drug diffraction peaks after spray drying at two-theta angles of about 12.3, 13.6, 15.2, 17.5, 18.8, 19.9, 21.7, 22.8 with high intensity were different from those of the pure material Figure 8(1).

\section{X-ray Photoelectron Spectroscopy (XPS)}

Figure 9 shows the wide scan spectra for raw CLT and spray dried CLT powder. The only clear difference between the spectra is the markedly changed content. The XPS data of elemental surface composition of CLT and spry dried CLT powder is shown in Table 2. These data show that spray dried CLT powder with a relatively higher concentration of $\mathrm{C}$ and $\mathrm{O}$, and lower concentration of $\mathrm{N}$, than the raw CLT surface. It also indicated small amount of HPMC was adsorbed to the surface of the particles (28).

The saturation solubility and in vitro dissolution of nanosized cilostazol powder

The saturation solubility of form A and combination of form $\mathrm{B}$ and $\mathrm{C}$ were assayed, to assure that form $\mathrm{B}$ and $\mathrm{C}$ possess distinct advantages over the form A (24). The combination of form $\mathrm{B}$ and $\mathrm{C}$ was prepared as follows: $0.6 \mathrm{~g}$ raw CLT was dispersed in $100 \mathrm{~mL}$ distilled water and then spray dried at $130^{\circ} \mathrm{C}$ as the inlet temperature. To assure the morphology of form A was same to combination of form $\mathrm{B}$ and form $\mathrm{C}$, form $\mathrm{A}$ was prepared at the same procedure, and the inlet temperature was set at $70^{\circ} \mathrm{C}$. The saturation solubility of form A and combination of form B and form $\mathrm{C}$ were shown in Table 3. From table 3 we can see that, the saturation solubility of combination of form $\mathrm{B}$ and form $\mathrm{C}$ (the ratio of form $\mathrm{C}$ to form $\mathrm{B}$ is about $4: 1$ shown in table 5 ) was 1.5 fold compared with that of form A.

In order to determine whether the goal of improving the rate of dissolution of CLT is achieved, the results of the in vitro dissolution of powders of different particle sizes are shown in Figure 10. The rate of dissolution of raw CLT, with particles in the micrometer range, was very low, only $20 \%$ of the drug was dissolved in the first $10 \mathrm{~min}$; the formulation of the spray dried 1232, 667, $326 \mathrm{~nm}$ powders of CLT exhibited dissolution of $72 \%, 87 \%$ and $98 \%$, respectively. The formulation of the $326 \mathrm{~nm}$ CLT spray dried powder significantly improved the dissolution rate, since almost $100 \%$ of the drug dissolved in the first 10min (Figure 10). So, the results indicate that a reduction in particle size ( at same time there are effectes of form change and presence of excipients) can produce a huge improvement in the dissolution rate.

Table 2. Atomic surface composition of powders as determined by XPS

\begin{tabular}{cccc}
\hline Sample & \multicolumn{3}{c}{ Surface coverage (atom \%) } \\
& $\mathrm{C}$ & $\mathrm{N}$ & $\mathrm{O}$ \\
\hline CLT & 74.12 & 12.19 & 13.69 \\
Spry dried powder & 75.48 & 9.57 & 14.96 \\
\hline
\end{tabular}

\begin{tabular}{clllll}
\hline \multicolumn{3}{c}{ Table 3. Saturation solubility of different crystalline forms and different particle size spray dried powders $(\mathrm{n}=3)}$. \\
\hline \multicolumn{3}{c}{ crystalline form } & \multicolumn{1}{c}{ Mean particle size $(\mathrm{nm})$} \\
\hline Saturation solubility & form A & form B and form C & 1282 & 667 & 326 \\
$(\mu \mathrm{g} / \mathrm{mL})$ & $3.9 \pm 0.2$ & $5.3 \pm 0.6$ & $5.7 \pm 0.3$ & $9.8 \pm 0.5$ & $23.1 \pm 0.6$ \\
\hline
\end{tabular}



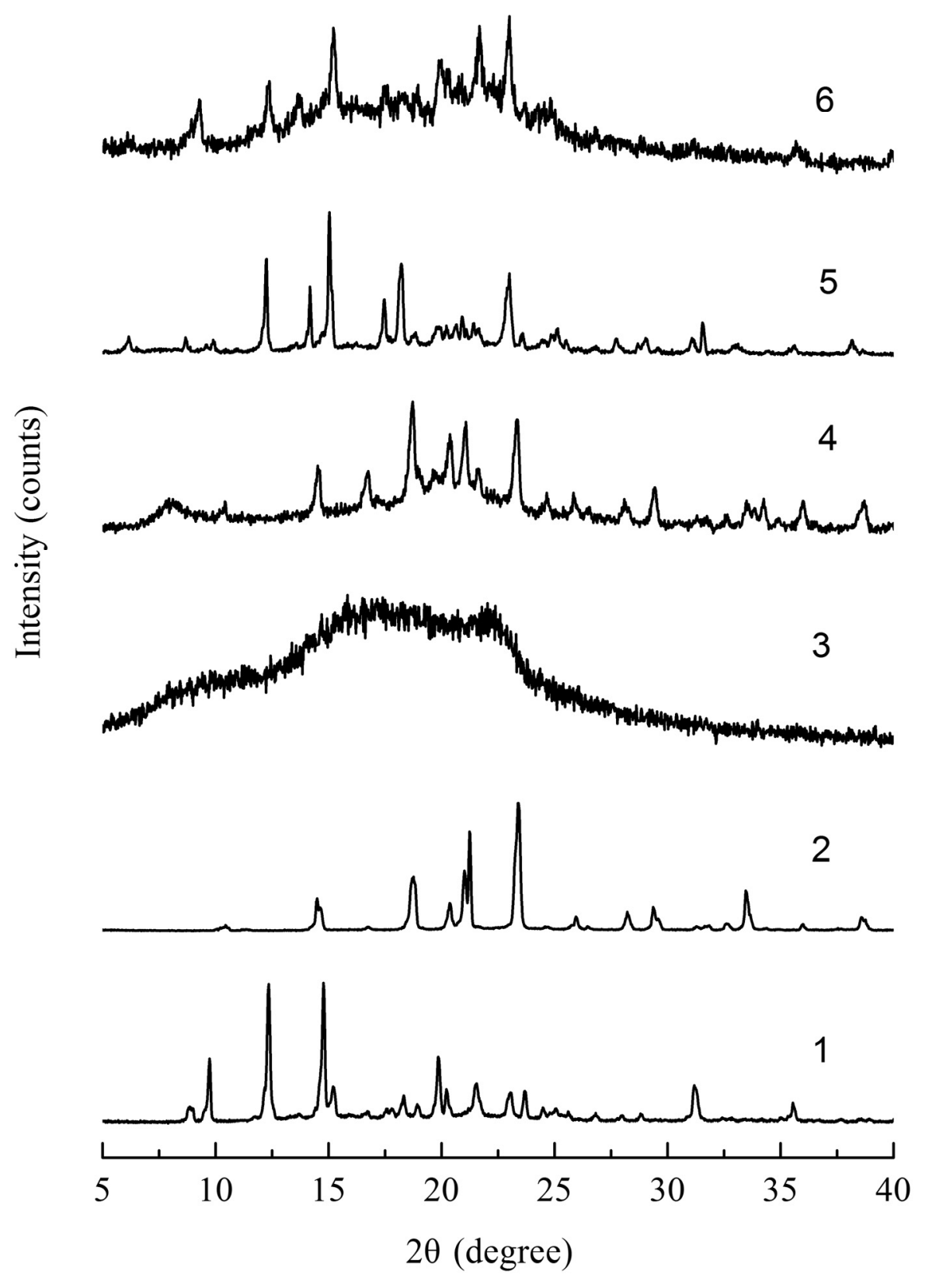

Figure 8. XRD spectrum of (1) raw CLT (form A), (2) mannitol, (3) HPMC, (4) blank excipients, (5) the mixture of CLT (form A) and excipients and (6) spray dried CLT powder. 


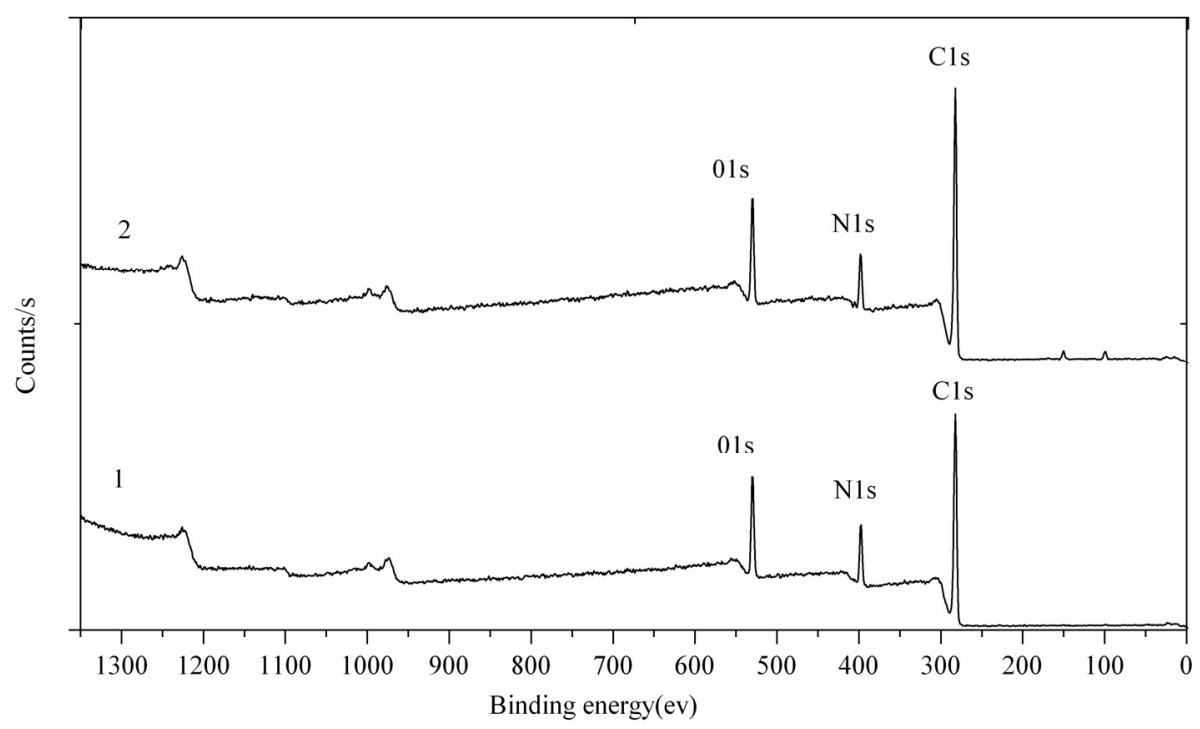

Figure 9. Wide scan spectrum for (1) CLT and (2) spray dried CLT powder

\begin{tabular}{cccccc}
\hline \multicolumn{6}{l}{ Table 4. The mean hardness, thickness, friability, disintegration time and weight of tablets $(\mathrm{n}=6)$} \\
\hline & $\begin{array}{c}\text { Hardness } \\
(\mathrm{kg})\end{array}$ & $\begin{array}{c}\text { thickness } \\
(\mathrm{cm})\end{array}$ & $\begin{array}{c}\text { Friability } \\
(\%)\end{array}$ & $\begin{array}{c}\text { disintegration } \\
\text { time }(\mathrm{min})\end{array}$ & weight $(\mathrm{mg})$ \\
\hline Nanosized tablets & $5.1 \pm 0.4$ & $0.16 \pm 0.02$ & $1.80 \pm 0.1$ & $23 \pm 2$ & $116 \pm 2$ \\
Nanosized crystalline tablets & $4.7 \pm 0.3$ & $0.15 \pm 0.03$ & $1.76 \pm 0.2$ & $21 \pm 3$ & $117 \pm 3$ \\
\hline
\end{tabular}

In vitro dissolution of nanosized cilostazol tablets The amount of drug incorporated in the tablets was $50 \mathrm{mg}$, which is the same as the pharmacological dose of the marketed tablet. The characterization of tablets is shown under table 4. The dissolution is intended to take place under sink conditions normally considered to occur in a volume of dissolution medium at least 3 times the saturation volume. Regarding the amount of CLT in the tablet (50mg) and $0.3 \%$ SDS, this medium was used to ensure sink conditions during the dissolution rate testing. The experiment showed that there was a higher dissolution rate for tablets containing the nanosized crystalline CLT powder compared with those containing the micronized drug (as shown in Figure 11). We can see that the dissolution rate of the spray dried powder is the same to the nanosized crystalline tables ( $90 \%$ in 30 minutes), which indicates that the tableting procedure did not affect the dissolution rate. During the preparation of tablets, the spray dried powder with lactose and croscarmellose sodium as filling agents can be compressed easily which contributed to the smooth sphere property with supported by Piera Di Martino et al. and Paradkar AR et al. (29-30).

\section{Bioavailability}

The bioavailability of CLT tablets prepared using spray dried nanosized crystalline tablets after oral administration to dogs was markedly increased compared with that produced by nanosized tablets and commercial tablets. The serum concentration-time profiles and the pharmacokinetic parameters of cilostazol following the oral administration of the tablets to beagle dogs are presented in Table 5 and Figure 12. The Cmax and $\mathrm{AUC}_{0-48 \mathrm{~h}}$ of CLT nanosized crystalline tablets were 2.1 fold and 1.9 fold, and 3.0 fold and 2.3 fold compared with those of the nanosized tablets and commercial tablets, respectively. 


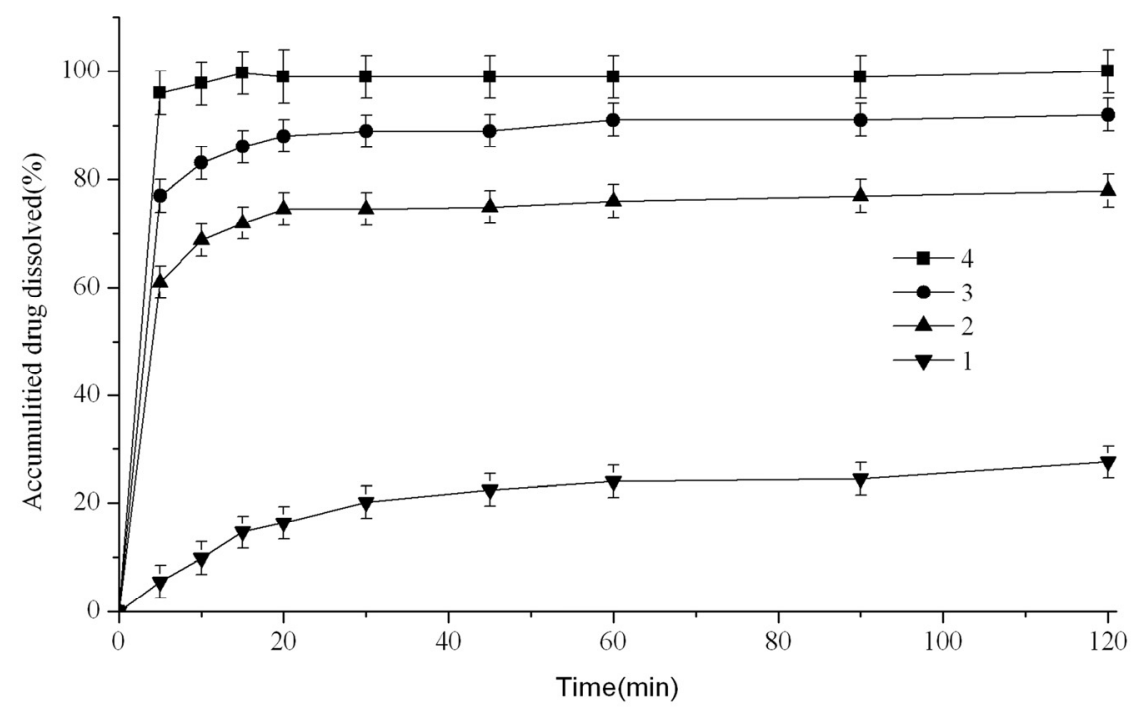

Figure 10. Dissolution profiles of different particle size spray dried powders (Mean \pm S.D. $n=3$ ). (1) spray dried pure material powder, (2) spray dried $1232 \mathrm{~nm}$ powder, (3) spray dried $667 \mathrm{~nm}$ powder and (4) spray dried $326 \mathrm{~nm}$ powder

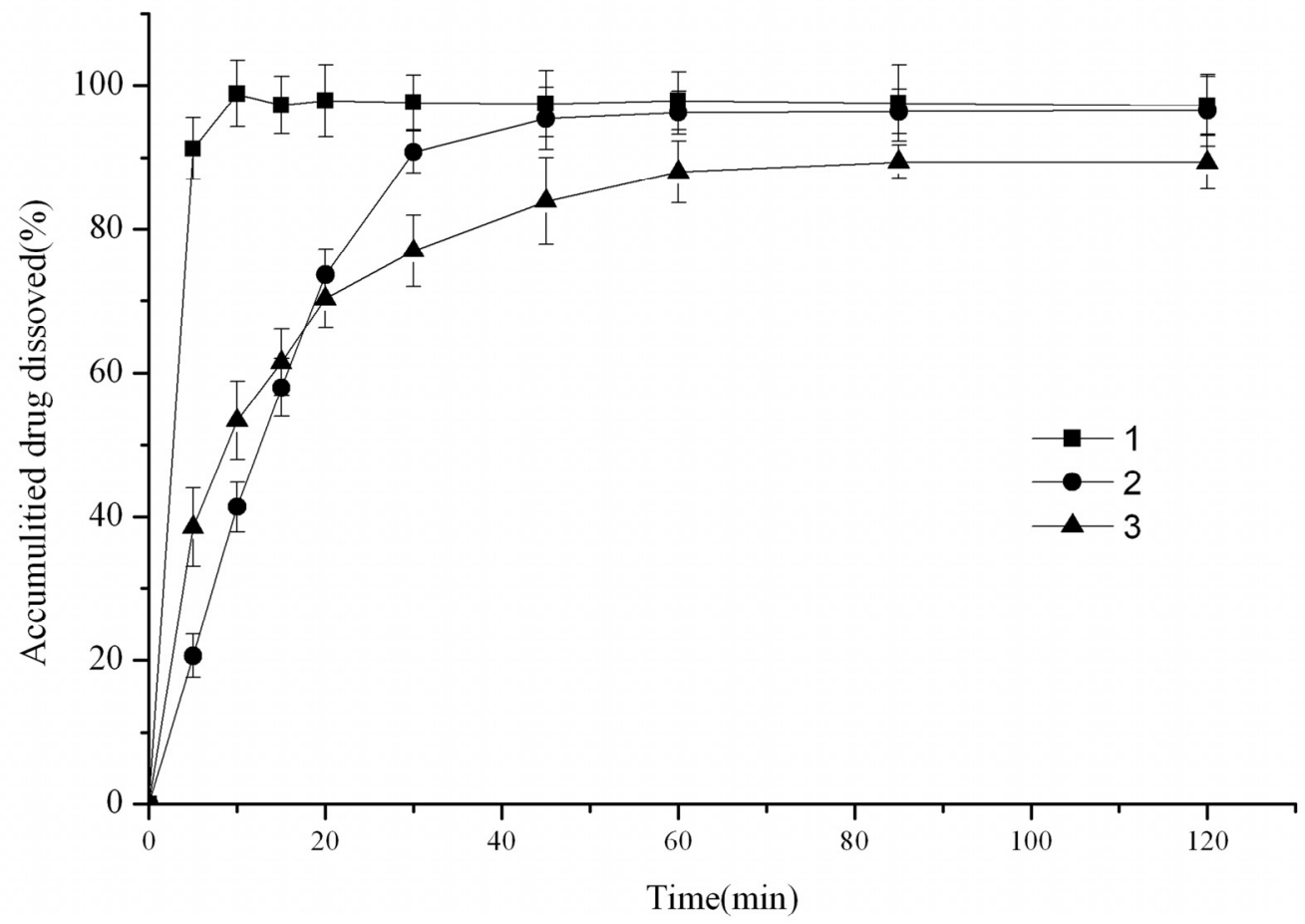

Figure 11. Dissolution profiles of (1) spray dried powder, (2) commercial tablets and (3) nanosized cilostazol tablets (Mean \pm S.D. $\mathrm{n}=3$ ). 
Table 5. Pharmacokinetic parameters of commercial tablets, nano-sized tablets and nanosized crystalline tablets after oral administration in beagle dogs, Mean \pm S.D., $n=6$

\begin{tabular}{cccc}
\hline Pharmacokinetic parameter & Commercial tablets & Nanosized tablets & Nanosized crystalline tablets \\
\hline $\mathrm{AUC}_{(0-48)}(\mathrm{ng} \mathrm{h} / \mathrm{mL})$ & $6384.9 \pm 1526.3$ & $7668.1 \pm 2409.5$ & $14572.9 \pm 5799.8$ \\
$\mathrm{Cmax}(\mathrm{ng} / \mathrm{mL})$ & $575.1 \pm 137.3$ & $787.9 \pm 29.8$ & $1726.1 \pm 480.3$ \\
$\operatorname{tmax}(\mathrm{h})$ & $2.6 \pm 1.0$ & $2.42 \pm 0.8$ & $2.01 \pm 1.0$ \\
\hline
\end{tabular}

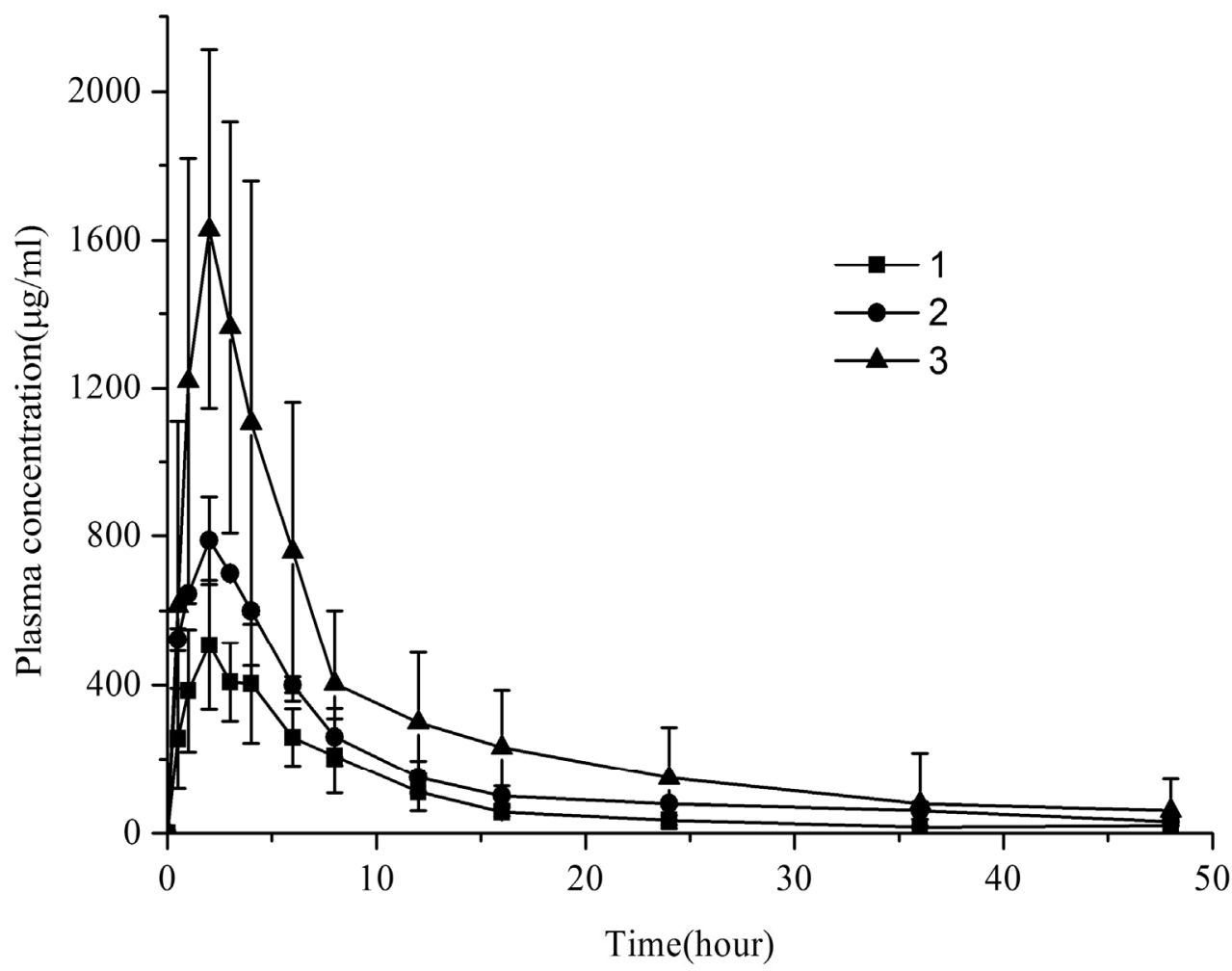

Figure 12. Serum concentration-time profiles of cilostazol after oral administration of the tablets at a dose of 100 $\mathrm{mg} /$ body in beagle dogs. Results are expressed as the mean with the bar showing S.D. values of six experiments. Keys: (1) commercial tablets, (2) nanosized tablets, (3) nanosized crystalline tablets.

\section{DISCUSSION}

\section{Preparation and particle size of nanosuspension} The CLT nanosuspension was prepared by the combination of anti-solvent precipitation and $\mathrm{HPH}$, and the method consist of two steps. First step, anti-solvent precipitation process. Preliminary precipitation experiments were carried out by varying the power input, times of ultrasonication and precipitation temperature. Precipitation at 400
$\mathrm{W}$ for intermittent sonication of $3 \mathrm{~s}$ at every $2 \mathrm{~s}$ intervals for a total sonication times of 30 times was found to be the most optimal. During preparation process, the precipitation temperature can also affect the average particle size of nanocrystals. Dengning Xia et al. investigation showed that when the precipitation temperature changed from 35 to $3^{\circ} \mathrm{C}$, the particle size was reduced from $4.43 \mu \mathrm{m}$ to $211 \mathrm{~nm}$, indicating that the lower the temperature, the smaller the crystals. So, 
all the experiments were carried out at $3^{\circ} \mathrm{C}$. From figure 3 , we can see that the mean particle size of suspensions prepared by precipitation is $680 \mathrm{~nm}$. It was difficult to produce CLT nanocrystals with a narrow particle size only by antisolvent precipitation under sonication, therefore the CLT suspensions was further homogenized after sonication. In our study, after HPH, the particle size of suspensions reduced to $326 \mathrm{~nm}$. It is evident that the uniformity of CLT particle size is significantly improved after homogenization, which is consistent with the findings of Yinghui Liu et al.(32).

HPMC E5 was selected the most successful of all the stabilizing agents studied as far as the formation of CLT suspensions. HPMC played a key role in inhibiting the growth of CLT nanocrystals which can be explained by a steric barrier. HPMC is a polymer containing lots of methoxyl and hydroxypropyl groups, and the hydrophobic parts have good affinity for drug particles and can be adsorbed onto the drug particle surface providing an effective steric barrier against growth(33).

\section{Mechanism of dissolution enhancement Morphology of CLT nanocrystals}

As shown in Figure 4D, spherical smooth CLT powder with many pores obtained by spray drying. From the results of Nitrogen adsorption, the CLT spray dried powder, as shown in Figure 5(1), were porous sphere with high BET surface area $\left(10.2 \mathrm{~m}^{2}\right.$ $\mathrm{g}^{-1}$ ) compared with that of raw CLT. According to Noyes-Whitney equation, when the powder was dispersed in the media, the water penetrates into the powder quickly via the pores with a huge surface area. Besides the increasing in surface area due to the formation of nano-sizing drug particles, the surface-active agents (shown in Figure 9 and Table 2) may have contributed to the increase in dissolution rate due to the improved wettability of the drug(34). Therefore, the properties of morphology of CLT nanocrystals showed a great advantage on dissolution behaviour.

\section{The existing form of CLT nanocrystals}

Stowell et al. (27) reported three different polymorphs of CLT (form A, B and C) with melting onset temperatures of $159{ }^{\circ} \mathrm{C}, 136^{\circ} \mathrm{C}$ and $146{ }^{\circ} \mathrm{C}$, respectively. In order to nullify the presence of amorphous form, the physical state of the spray dried powder (the ratio of form $\mathrm{C}$ and form $\mathrm{B}$ is about 4:1) was examined with a low temperature DSC. From figure 13 shown, there is not amorphous form but only form C and B of CLT in spray dried powder. The amorphous cilostazol of DSC in the US patent (24) shows the glass transition onset temperature is $31.52^{\circ} \mathrm{C}$ and exotherm peak temperature is about $35^{\circ} \mathrm{C}$. There are not any exothermic peaks in our DSC thermogram. Therefore, there is no amorphous cilostazol in spray dried powders.

The formation of form $\mathrm{C}$ and form $\mathrm{B}$ can increase the saturation solubility compared with form A, the coarse drug and, so, faster dissolution profiles were expected. As shown in Figure 7, the transition of the crystalline state to form $\mathrm{C}$ and form $\mathrm{B}$ takes place successfully during the spray drying process. The XRD investigation (Figure 8) gave similar results to the DSC study. Therefore, the existing form of CLT nanocrystals showed a great advantage on dissolution behaviour.

\section{Saturation solubility, in vitro dissolution}

In our study, both morphology and the existing form of CLT nanocrystals played important role in saturation solubility and in vitro dissolution behaviour. Figure 14 shows the relationship between different particle sizes and the saturation solubility and dissolution rate. Figure 14 indicates both the saturation solubility and dissolution rate were determined by the mean particle size. With the particle size decreased, dissolution rate increased significantly, when the particle size reduced to less than $667 \mathrm{~nm}$, accumulated drug dissolved were above $85 \%$ for the first 10 minutes. From Figure 14 and Table 3, the saturation solubility of different particle sizes is of significant difference. Especially when the particle size achieve to $1 \mu \mathrm{m}$, there was a threshold, the saturation solubility improved remarkably.

Quantification of polymorph B and C in crystalline form of CLT was employed by Gauss function of ORIGIN 7.5 software in DSC spectrum (Figure 7) (35). The result in Table 6 shows the percent of form $\mathrm{A}, \mathrm{B}$ and $\mathrm{C}$ in the spray-dried powders prepared in different inlet temperatures during spray drying process. Because spray dried powder of CLT in the XRD showed the peaks of polymorph $\mathrm{A}, \mathrm{B}$ and $\mathrm{C}$, the quantification of polymorph $\mathrm{B}$ and $\mathrm{C}$ can not be evaluated. 


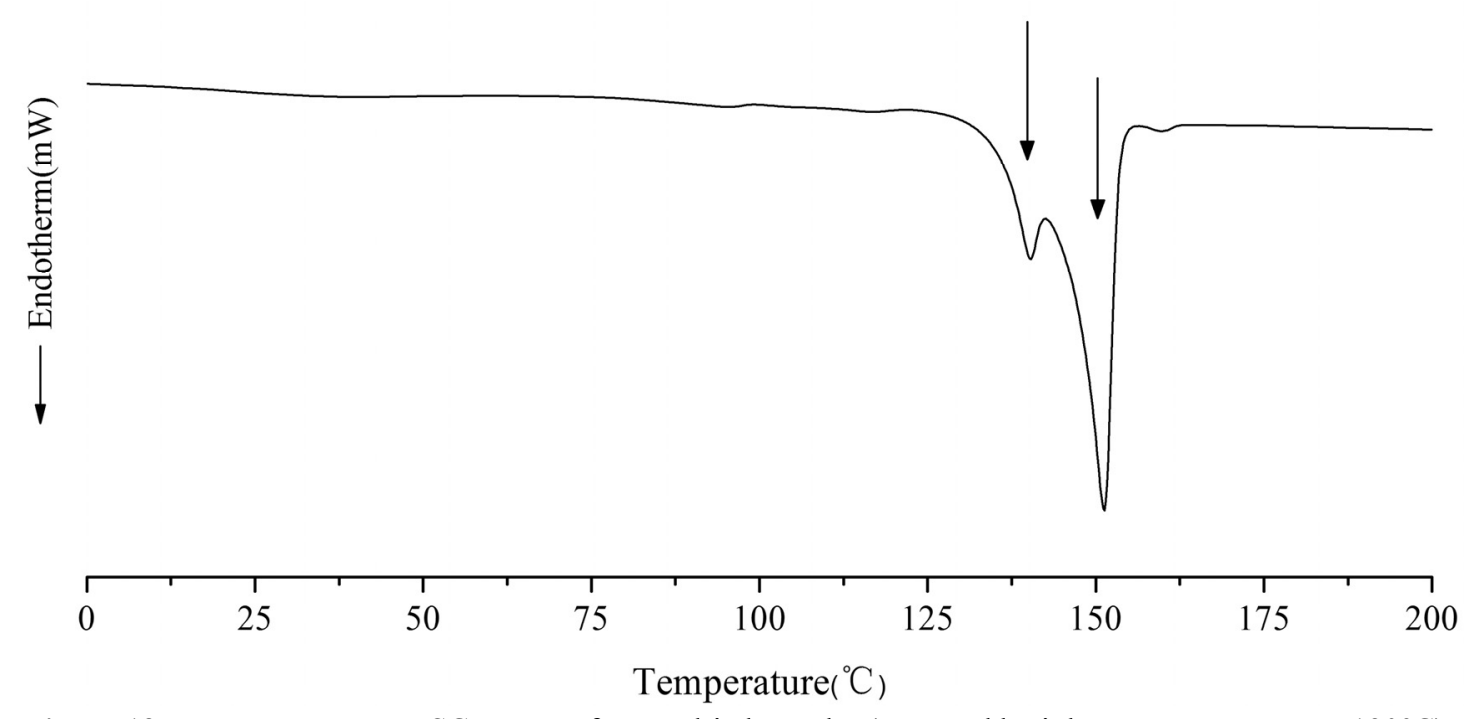

Figure 13. Low temperature DSC curves of spray dried powder (prepared by inlet temperature set as $130^{\circ} \mathrm{C}$ ).

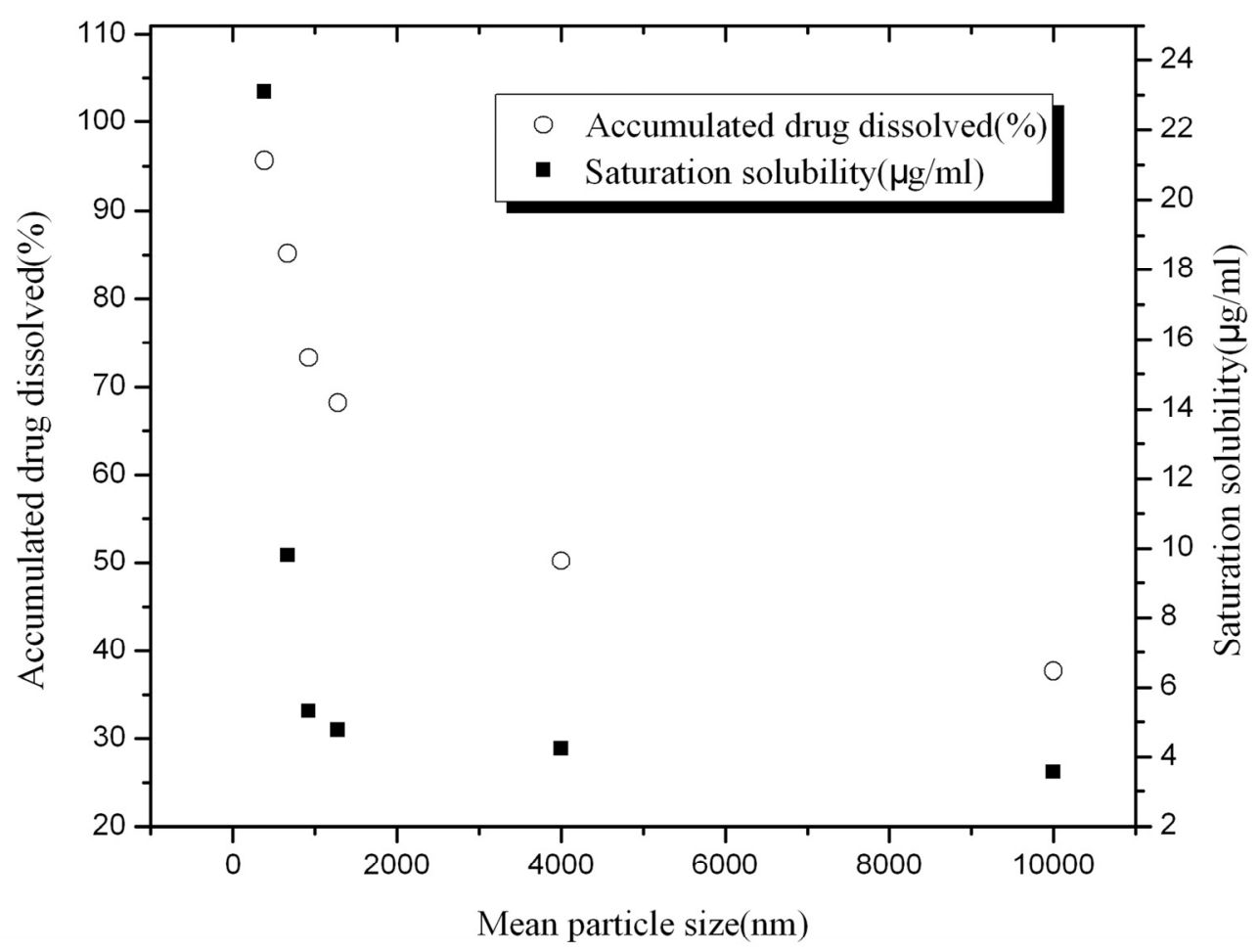

Figure 14. Accumulated drug dissolved and saturation solubility as a function of mean particle size (the powders were prepared at the same inlet temperature $\left(T=130^{\circ} \mathrm{C}\right)$ during spray drying process $)(\mathrm{n}=3)$. 
Figure 15 shows the relationship between the combination of polymorph $\mathrm{B}$ and $\mathrm{C}$ and the saturation solubility and dissolution rate. With the ratio of combination of polymorph $\mathrm{B}$ and $\mathrm{C}$ increasing, dissolution rate improved largely, when the ratio above $92 \%$, accumulated drug dissolved were higher than $80 \%$ for the first 10 minutes. From Figure 14, the saturation solubility of polymorph $\mathrm{B}$ and $\mathrm{C}$ in spray dried powder with different ratio is of significant difference. When the ratio achieved to $100 \%$, the saturation solubility was about 5-fold higher than that of form $\mathrm{A}$ at the same particle size. So, the results indicate that preferred polymorph B and C of CLT can make a good improvement in the dissolution rate and saturation solubility.

\section{Bioavailability study in beagle dogs}

The Cmax and $\mathrm{AUC}_{0-48 \mathrm{~h}}$ of CLT nanosized tablets was 1.4 fold and 1.2 fold compared with those of the commercial tablets, respectively. As shown in Figure 12(2) and Figure 12(1), nanosized tablets was found to exhibit better bioavailability as compared to commercial tablets, because of reduced particle size and porous structure with increased surface area. The Cmax and $\mathrm{AUC}_{0-48 \mathrm{~h}}$ of CLT nanosized crystalline tablets was 2.1 fold and 1.9 fold compared with those of the nanosized tablets, respectively.

Table 6. The mean percent of form A, B and C in the spray-dried powders prepared in different inlet temperatures during spray drying process shown in Figure 7. $(n=3)$

\begin{tabular}{ccccccc}
\hline Inlet temperature $\left({ }^{\circ} \mathrm{C}\right)$ & 70 & 90 & 100 & 110 & 130 & 140 \\
\hline form A $(\%)$ & 100 & 29.7 & 17.4 & 14.2 & 0 & 29.3 \\
form B (\%) & 0 & 7.6 & 11.7 & 13.5 & 17.9 & 19.2 \\
form C (\%) & 0 & 62.7 & 70.9 & 72.3 & 82.1 & 51.5 \\
\hline
\end{tabular}

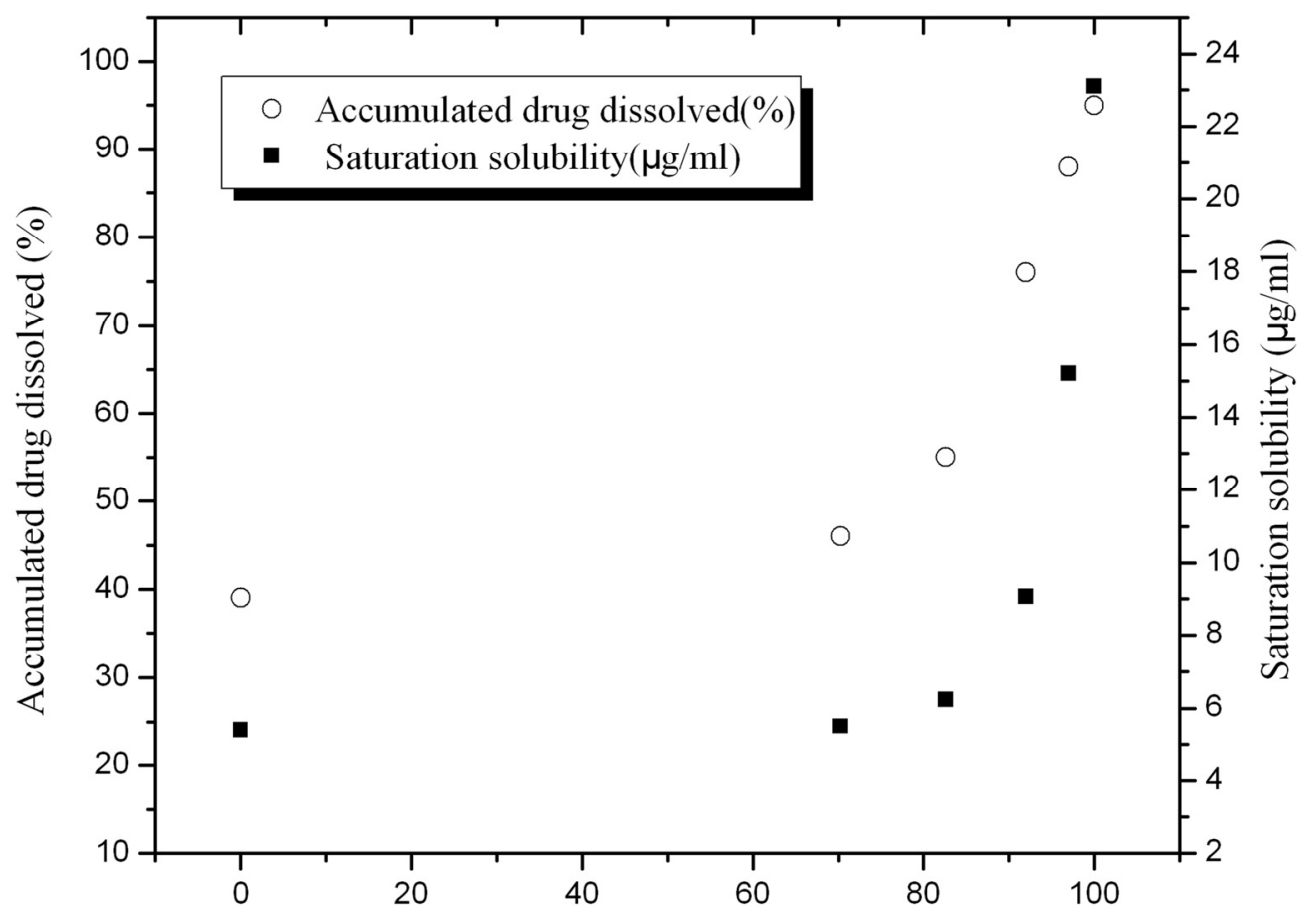

The ratio of combination of polymorph $\mathrm{B}$ and $\mathrm{C}$ in the spray powder (\%)

Figure 15. Accumulated drug dissolved and saturation solubility as a function of the ratio of combination of polymorph $\mathrm{B}$ and $\mathrm{C}$ (the powders were prepared to acquire the same particle size at different inlet temperatures during spray drying process) $(n=3)$. 
As shown in Figure 12(3) and Figure 12(2), nanosized crystalline tablets was found to exhibit better bioavailability as compared to nanosized tablets, because of its greater dissolution rate owing to its transition of the crystalline state to form $\mathrm{C}$ and form B. It is evident that nanosized crystalline tablets and nanosized tablets were rapidly absorbed and reached maximum concentrations by $2 \mathrm{~h}$ and $2.4 \mathrm{~h}$ in dogs as compared with commercial tablets (shown in Table 4).

As shown in Figure 12, nanosized crystalline tablets were found to exhibit better bioavailability as compared to commercial tablets, because of its greater dissolution rate owing to its transition of the crystalline state to form $\mathrm{C}$ and form $\mathrm{B}$, reduced particle size and porous structure with increased surface area. This was in agreement with the in-vitro dissolution studies.

\section{CONCLUSION}

The anti-solvent-high-pressure homogenization technique was employed successfully to produce cilostazol nanosuspensions. The particle size of the nanocrystals is highly dependent on the homogenization parameters. By employing an optimized homogenization pressure and cycle number, nanosuspensions with mean diameters of about $300 \mathrm{~nm}$ can be prepared. From the DSC and XRD data, we can see that, after the spray drying process the existing form of CLT was changed. Meanwhile, from the dissolution profiles of particles of different sizes, the results show that the reduction of particle size and the crystalline transition can hugely improve the dissolution rate. The bioavailability of CLT tablets prepared using spray dried nanosized crystalline tablets after oral administration to dogs was markedly increased compared with that produced by nanosized tablets and commercial tablets. From our investigation, forming crystalline form nanocrystals can improve the bioavailability further more than only forming nanocrystals. We believe that the present study will be helpful in designation of oral drug delivery systems (especially for crystalline drugs).

\section{ACKNOWLEDGEMENTS}

Our work was supported by the National Basic Research Program of China (973 Program) (No. 2009CB930300) and Major National Platform for Innovative Pharmaceuticals (No. 2009ZX09301-012). We would like to thank Dr.
David Jack for correcting and checking manuscript.

\section{REFERENCES}

1. Patravale, V.B., Date, A.A., Kulkarni, R.M. Nanosuspensions: a promising drug delivery strategy. J. Pharm. Pharmacol, 2004; 56: 827-840.

2. Rabinow BE. Nanosuspensions in drug delivery. Nature rev Drug Disc, 2004; 3: 785-796.

3. A.A. Noyes, W.R. Whitney. The rate of solution of solid substances in their own solutions, J. Am. Chem. Soc, 1897; 19: 930-934.

4. Dressmann JB, Reppas C. In vitro-in vivo correlations for lipophilic, poorly water-soluble drugs. Eur J Pharm Sci, 2000; 11: 73-80.

5. Kesisoglou, F., Panmai, S., Wu, Y. Nanosizing — oral formulation development and biopharmaceutical evaluation. Adv. Drug Deliv. Rev, 2007; 59: 631-644.

6. Xiong, R., Lu,W., Li, J.,Wang, P., Xu, R., Chen, T., Preparation and characterization of intravenously injectable nimodipine nanosuspension, Int. J. Pharm. 2008; 350:338-343.

7. Krause, K., Müller, R.H. Production and characterization of highly concentrated nanosuspensions by high pressure homogenization. Int. J. Pharm, 2001; 214: 21-24.

8. Guo, R., Zhang, L.Y., Jiang, Zh.P., Cao, Y., Ding, Y., Jiang, X.Q. Synthesis of alginic acid-poly[2-(diethylamino) ethyl methacrylate] monodispersed nanoparticles by a polymer-monomer pair reaction system. Biomacromolecules, 2007; 8: 843-850.

9. Muller RH, Jacobs C, Kayser O. Nanosuspension as particulate drug formulations in therapy rationale for development and what we can expect for the future. Adv Drug Deliv Rev, 2001; 47:3-19.

10. Van Eerdenbrugh, B., Froyen, L.,Martens, J.A., Blaton, N., Augustijns, P., Brewster,M., Van den Mooter, G. Characterization of physico-chemical properties and pharmaceutical performance of sucrose co-freeze-dried solid nanoparticulate powders of the anti-HIV agent loviride prepared by media milling. Int. J. Pharm, 2007; 338: 198-206.

11. Van Eerdenbrugh, B., Van den Mooter, G., Augustijns, P. Top-down production of drug nanocrystals: nanosuspension stabilization, miniaturization and transformation into solid products. Int. J. Pharm, 2008; 364: 64-75.

12. U. Hayato, T. Toshio, K. Yukio, H. Hiroyoshi, Biochem. Pharmacol, 1984; 33: 3339.

13. Y. Kimura, T. Tani, T. Kanbe, K. Watanabe. Arzneimittel forschung, 1985; 35: 1144.

14. E.M. Sorkin, A. Markham, Drugs Aging, 1999; 14: 63.

15. G.L. Amidon, H. Lennernas, V.P. Shah, J.R. Crison. A theoretical basis for a biopharmaceutic drug 
classification: the correlation of in vitro drug product dissolution and in vivo bioavailability, Pharm. Res, 1995; 12: 413-420.

16. T. Shimizu, T. Osumi, K. Niimi, K. Nakagawa, Physico-chemical properties and stability of cilostazol, Arzneimittelforschung 1985, 35: 11171123.

17. H. Toyobuku, I. Tamai, K. Ueno, A. Tsuji, Limited influence of Pglycoprotein on small-intestinal absorption of cilostazol, a high absorptive permeability drug, J. Pharm. Sci. 2003; 92: 22492259.

18. S.L. Bramer, W.P. Forbes. Relative bioavailability and effects of a high fat meal on single dose cilostazol pharmacokinetics, Clin. Pharmacokinet, 1999; 37 (Suppl 2): 13-23.

19. Jun-ichi Jinno, Naoki Kamada. Effect of particle size reduction on dissolution and oral absorption of a poorly water-soluble drug, cilostazol, in beagle dogs. J. Control. Release, 2006; 111: 56 - 64.

20. Jun-ichi Jinno, Naoki Kamada. In vitro-in vivo correlation for wet-milled tablet of poorly water-soluble cilostazol. J. Control. Release, 2008; 130: 29-37.

21. Samir G. Patel and Sadhana J. Rajput. Enhancement of Oral Bioavailability of Cilostazol by Forming its Inclusion Complexes. AAPS Pharm SciTech, 2009; Vol. 10, No. 2, June 2009.

22. Min-Soo Kim, Sibeum Lee, Jeong-Sook Park, Jong-Soo Woo, Sung-Joo Hwang. Micronization of cilostazol using supercritical antisolvent (SAS) process:Effect of process parameters. Powder Technology, 2007; 177: 64-70.

23. K. Chen, X. Zhang, J. Pan, W. Yin, J. Cryst. Growth 274 (2005) 226.

24. G.W. Stowell, R.R. White, US Patent. 2003:6531603.

25. Andrej Dolenc, Julijana Kristl, $\mathrm{Sa}^{2}$ sa Baumgartner, Odon Planin sek. Advantages of celecoxib nanosuspension formulation and transformation into tablets. Int. J. Pharm, 2009; 376:204-212.

26. Hai Xia Zhang, Jie XinWang, Zhi Bing Zhang, Yuan Le, Zhi Gang Shen, Jian Feng Chen. Micronization of atorvastatin calcium by antisolvent precipitation process. Int. J. Pharm, 2009; IJP-10540; No. of Pages8.

27. G.W. Stowell, R.J. Behme, S.M. Denton, I. Pfeiffer, F.D. Sancilio, L.B. Whittall, R.R. Whittle. J. Pharm. Sci, 2002; 91: 2481.

28. M.E. Morales , M.A. Ruiz, I.Oliva, M.Oliva, V. Gallardo. Chemical characterization with XPS of the surface of polymer microparticles loaded with morphine. Int. J. Pharm, 2007; 333: 162-166.

29. Piera Di Martino, Mara Scoppa, Etienne Joiris, Giovanni F. Palmieri, Cyrille Andres, Yvette Pourcelot, Sante Martelli. The spray drying of acetazolamide as method to modify crystal properties and to improve compression behaviour. Int. J. Pharm, 2001; 213 : 209-221.

30. Paradkar AR, Pawar AP, Chordiya JK, Patil VB, Ketkar AR. Spherical crystallization of celecoxib. Drug Dev Ind Pharm, 2002; Vol. 28, No. 10: pp.1213-1220.

31. Dengning Xia, Peng Quan, Hongze Piao, Hongyu Piao, Shaoping Sun. Preparation of stable nitrendipine nanosuspensions using the precipitation-ultrasonication method for enhancement of dissolution and oral bioavailability. Eur. J. Pharm. Sci, 2010; 40: 325-334.

32. Yinghui Liu, Changshan Sun, Yanru Hao, Tongying Jiang, Li Zheng, Siling Wang. Mechanism of Dissolution Enhancement and Bioavailability of Poorly Water Soluble Celecoxib by Preparing Stable Amorphous Nanoparticles. J Pharm Pharmaceut Sci, 2010;13(4):589 - 606.

33. Wong S M, Kellaway IW, Murdan S. Enhancement of the dissolution rate and oral absorption of a poorly water soluble drug by formation of surfactant-containing microparticles.Int $\mathrm{J}$ Pharm, 2006; 317: 61-68.

34. Anne Zimmermann, Anna Millqvist-Fureby, Michiel Ringkjøbing Elema, Tue Hansen,Anette Müllertz, Lars Hovgaard. Adsorption of pharmaceutical excipients onto microcrystals of siramesine hydrochloride: Effects on physicochemical properties. Eur. J. Pharm. Biopharmaceutics, 2009;71: 109-116. 35. D. Giron. J. Therm. Anal. Calorim. 2002; 68, p. 353. 